\title{
Racial, Gender, and Professional Diversification in the Forest Service from 1983 to 1992
}

\author{
Jennifer C. Thomas and Paul Mohai
}

The United States Department of Agriculture Forest Service traditionally has been dominated by white, male foresters, particularly in its professional and leadership ranks. Beginning in the mid-1970s, however, civil rights legislation, lawsuits, and statutes that mandated interdisciplinary planning collectively impelled the agency to begin diversifying by race, gender, and profession. This study attempts to quantify the progress the agency has made in workforce diversification since the early 1980s by grouping Forest Service job series into categories and tracking changes in these categories over time. The study reveals that the numbers of employees in "nontraditional" Forest Service fields (e.g., the social and biological sciences) increased markedly, but that these employees remain vastly outnumbered by employees in traditional fields such as forestry. The number of women in the agency also increased greatly, but women made much greater gains in administrative support positions than in jobs that put them in the pipeline for leadership positions. They remain vastly overrepresented in clerical and administrative positions and highly underrepresented in professional and technical positions. People of color made gains in nearly all job categories, but, like women, remain significantly overrepresented in jobs that will not lead to leadership positions. Thus, while aggregate numbers show greater diversity in the Forest Service workforce, a more detailed analysis reveals that the leadership ranks are still the domain of white, male foresters.

Traditionally, the United States Department of Agriculture Forest Service's land management policies have been developed and implemented by white, male foresters. Ample evidence exists to illustrate this point. In his classic 1960 study of administrative behavior in the Forest Service, Herbert Kaufman found that 90\% of the agency's professionals were trained foresters. Kaufman (1960, p. 214) observed:

Not only are line officers, timber management staff men, and fire control specialists all foresters, as one would expect, but so are the specialists in range management ..., wildlife management ..., personnel management, administrative management ..., information and education, budgeting, recreation management ... and in other functions.

The overwhelming majority of these foresters have been men. The Forest Service did not employ a female forester until 1957, and even in 1978 less than $2 \%$ of the agency's foresters were women (Burrus-Bammel, 1989). Clearly, this situation has existed in the agency from the beginning. The following appeared in The Forest Ranger's Catechism in Region Five, in 1931:

Can a woman become a forest ranger? No. Women are not appointed by the Forest Service as members of the field force even if they pass the civil service examination (James, 1991, p. 16). 
Of these male foresters, nearly all were white. In 1963, only five of 2,400 Forest Service employees above GS-12 were people of color (West, 1992). In 1967 only one African-American forester worked for the agency (Mayberry, 1975).

Today, many scholars and agency observers claim the Forest Service workforce has changed, becoming diverse in profession, gender, and race. Tipple and Wellman (1991, p. 424) stated that there is now "greater heterogeneity in the organizational leadership cadre," and that "women and minorities are actively being recruited and moved through the system." Kennedy (1991) claimed that there has been an influx of nontraditional professionals and women into the Forest Service. A report by the National Forest Products Association provides some data documenting this diversification, and concludes that "[a]s time passes, it is logical to expect that nontraditional resource professionals, women, and minorities will become more involved in management decisions" (Gladics, 1991, p. 19). Brown and Harris (1992) posit that the changing workforce already has begun to affect the organization's value system and the dominant resource management paradigm. The agency leadership itself also claims there has been change: Former Forest Service Chief Dale Robertson said in 1988 that "we have more women and minorities moving into the upper grades of the Forest Service ... into our significant line and top staff positions" (Robertson, 1988).

However, none of these sources provides comprehensive statistics showing the extent and timing of workforce changes in recent years, nor have they documented the types of positions into which women and people of color have been hired. In order to fill these gaps in the literature, this study seeks to determine for the past decade trends in the composition of the Forest Service by profession, and trends in gender and racial diversification, noting particularly the types of jobs into which women and people of color have moved in the agency and their relative likelihood of reaching leadership positions. It is assumed that the goal of gender and racial diversification in the Forest Service is the proportional representation of diverse individuals at all levels and in all areas of the agency. This analysis will help assess whether that goal has been achieved.

In addition to providing detailed empirical data on diversification in the Forest Service, the results of this analysis may provide insight into potential changes in the agency's internal value orientation, which may affect agency decisionmaking. According to Twight, the Forest Service's traditional value orientation is based on adherence to the concepts of sustained yield and utilitarianism (1983). Twight (1983) and Brown and Harris (1992) argue that value orientation affects decisionmaking, and thus policy outcomes.

Several studies have documented differences in value orientation between foresters and other Forest Service professionals, and between men and women. For example, Kennedy found that entry-level wildlife and fisheries biologists "differed from their forester and range manager colleagues in professional allegiance, [and] acceptance of agency values ..." (1991, p. 166). McCarthy, Sabatier, \& Loomis (1991) documented modest differences between traditional and nontraditional professionals, finding, in particular, "a pro-environmental stance among wildlife biologists and hydrologists while foresters and civil engineers tend to occupy the other end of the spectrum" (p. 11). A 1990 survey by Brown and Harris (1993, p. 93) reported that "women in the Forest Service exhibit greater general environmental concern than men ..." even after controlling for age, years in the Forest Service, and professional identification (their emphasis). Female employees were significantly more likely than men to agree that "1) the agency should reduce timber harvest levels on National Forests, 2) preservation of old-growth forests should be advocated, and 3) designation of more wilderness should be promoted" (Brown \& Harris, 1993, p. 95). Two other studies found little to no difference between men and women in attitudes about general 
studies found little to no difference between men and women in attitudes about general environmental issues, but found that women did exhibit significantly more concem than men about local or community-based environmental problems (Mohai, 1992; Blocker \& Eckberg, 1989). However, unlike the clear differences found between men and women, at least two studies have concluded that there are few significant differences in environmental attitudes between people of color and whites (Mohai, Stillman, Jakes, \& Liggett, 1994; Mohai, 1990). Nevertheless, the results of the majority of studies showing significant differences in attitudes based on demographic and professional variation suggest that a significant increase in the numbers of nontraditional employees may change the collective value orientation of the Forest Service, and thus eventually alter policy outcomes.

In order to set the stage for our analysis, a brief background on the agency's diversification efforts is necessary. In the past 25 years, legislative and judicial mandates have required the agency to begin diversifying its workforce. The National Environmental Policy Act (NEPA) and the National Forest Management Act (NMFA), both passed in the 1970s, required the Forest Service to conduct interdisciplinary impact assessments and planning, respectively, thus creating a need for professionals other than foresters (Garcia, 1989). The Civil Rights Act of 1964, as amended by the Equal Employment Opportunity Act of 1972, required federal agencies to implement affirmative employment programs to eliminate the historic underrepresentation of people of color and women in the workforce. In 1973, a female Forest Service employee in Region 5 filed suit against the agency, charging that employment and training practices amounted to gender discrimination. As a result of this lawsuit, in 1981 the Forest Service's Region 5 office entered into a consent decree in which they agreed to take action to employ a workforce in that region that was comparable to the civilian labor force (United States Department of Agriculture, Forest Service, 1992a). All of these extemal forces have required the agency to hire employees different from the white, male foresters of Kaufman's day.

In response to these mandates, the Forest Service launched a number of programs to guide its diversification efforts. In the mid-1980s the Forest Service developed a Strategic Human Resource Guide, which called for preparing annual recruitment recommendations through 1991 and measuring progress toward employment goals (United States General Accounting Office, 1990). In 1987, the agency developed a program called "Work Force 1995: Strength Through Diversity," the goal of which is to achieve an "ideal" workforce as defined by the Civil Service Reform Act of 1978. The program emphasizes five areas for management focus: recruitment, retention, upward movement, organizational culture, and public awareness (United States Department of Agriculture, Forest Service, 1987). In 1990, the agency held a National Diversity Conference, entitled "All Together Now," in which 600 participants shared experiences and identified progress made in and problems with workforce diversification (United States Department of Agriculture, Forest Service, 1990). Also in 1990, the agency commissioned a National Work Force Diversity Task Force, which published a report ("Toward a Multicultural Organization") and an implementation plan. The implementation plan includes goals and strategies in six areas: training and development, work environment, outreach and recruitment, work and family, standards for accountability, and recognition (United States Department of Agriculture, Forest Service, 1992b). Through much of this period, the Forest Service also has attempted to increase its numbers of people of color through partnerships with the historically black "1890 colleges" and Native American colleges (United States Department of Agriculture, Forest Service, 1990). The purpose of this study is to determine just how effective these diversification efforts have been, both by tracking recent overall trends 
and by determining the types of jobs into which women and people of color have been hired.

\section{Methods}

Data for this study were compiled from the Forest Service's annual Workforce Data Books (1992c). The Data Books from 1983 through 1992 were used, since earlier books do not contain sufficiently detailed information. Note that the Forest Service did not compile workforce information during 1985 and 1987, so the graphs contain no data points for those years. Instead, lines were drawn between the data points for the preceding and succeeding years, with the assumption that the change was gradual and uniform. In all cases the data refer to "permanent employees" (called "career and careerconditional employees" in earlier Data Books), which includes all permanent full-time and part-time workers. Temporary and wage-grade employees are not considered, since their numbers were not well documented until the most recent Workforce Data Books. Also, due to the method of reporting in the Data Books, all people of color were considered together instead of by individual race. This masks discrepancies in representation of individual races, as discussed later.

In order to analyze changes in the Forest Service workforce, "job series" were grouped into nine categories and the number of total employees, women, and people of color in each category was tracked over time. Job series are assigned by the Forest Service to each entering employee, according to the type of work that the employee will be doing. There are education and experience qualifications for each series. All employees hired as wildlife biologists, for example, must have a degree in wildlife biology or a closely related field and are assigned the job series number 0486 (Martin, 1993). For this analysis, job series were grouped into the following nine categories: Administration, Biological Science, Clerical, Engineering, Forestry, Physical Science, Recreation, Range, and Social Science.

It should be noted, for those familiar with the Forest Service's own workforce categorization schemes, that the categories used in this study are not related to either PATCO $^{1}$ categories, which split employees by grade and type of work, or the line/staff delineation, ${ }^{2}$ which separates leadership positions from all others. Either of these categorization schemes would have been useful for our analysis; however, information regarding the total number, gender, and race of employees in these categories has not been tracked by the agency during recent years. Use of GS ratings ${ }^{3}$ to determine rates of promotion also would have been useful, but these were impossible to track due to different methods of reporting in each Workforce Data Book. Thus, each of the categories used in this paper may include professional, administrative, and/or technicallevel employees. ${ }^{4}$ Also, each category may include employees at any GS level and in either line or staff positions.

There are several limitations to the categorization approach used here. First, a few job series titles may not describe accurately the individuals to whom they are assigned. For example, the "General Biological Science" series (0401) are supervisory positions that may be filled by a forester, biologist, landscape architect, or other. Similarly, all district rangers and forest supervisors are assigned the job series number for forestry (0460), though this is less problematic since there are a relatively small number of them and the large majority are trained foresters. According to a personnel official at the Forest Service's headquarters, the use of job series data may underestimate slightly the number of foresters in the agency, since foresters sometimes fill positions with job series numbers other than 0460 (Martin, 1993). Also, looking at changes in 
numbers of each job series does not take into account changes that may be occurring within a profession. A change in the number of foresters, for example, does not describe changes taking place in the forestry field.

Despite these limitations, it was determined that job series data provide the best way to track workforce data over time to achieve the objectives of this study. The first objective was to track trends in the Forest Service's professional makeup over time. Clearly, the categorization approach used here provides a simple means for charting changes in the number of individuals in the major professions within the agency. The second objective was to determine trends in gender and racial diversification, as well as the types of positions into which women and people of color have moved. This also can be accomplished using the categories devised here. In the Forest Service, line officers are those who make policy decisions, while staff positions support the activities of the line officers. Traditionally, mid- to upper-level jobs in the Forestry, Engineering, and Range categories are most likely to lead to line positions. In contrast, Physical Science, Social Science, Recreation, and Biological Science represent nontraditional categories whose professionals are less likely to move into line positions (Kaufman, 1960; Gladics, 1992). Administration and Clerical positions have essentially no likelihood of being stepping stones to line positions. Thus, our categorization scheme allows a determination of whether, in the current diversification effort, the agency is placing women and people of color in support positions, nontraditional professional positions that may be stepping stones to line positions, or traditional professional jobs that place them on track for policymaking line positions.

\section{Results}

\section{Professional Diversification}

In order to determine how far the Forest Service has come in its efforts to diversify its professional workforce, this section analyzes the change in number of employees in the above-mentioned nine categories: Biological Science, Engineering, Forestry, Physical Science, Recreation, Range, Social Science, Clerical, and Administration.

Total Forest Service employment decreased in the early-1980s, but then increased in the late-1980s, such that the net change from 1983 to 1992 is near zero. The data for each category show several significant changes over the ten-year period, however. In general, the nontraditional fields (Biological Science, Recreation, Social Science, and Physical Science) gained the most new positions, while the traditional fields (Forestry, Range, and Engineering) lost many. Biological Science, for example, gained 1,268 employees between 1983 and 1992, for a 45.5\% increase. Likewise, Recreation increased by 264 employees, or $35.5 \%$, and Social Science by 32 employees, or $16.8 \%$. Physical Science is the only exception in the nontraditional group; it lost 27 employees, or $2.0 \%$. On the other hand, employment in all of the traditional fields decreased. Engineering lost the most, decreasing by 1,147 employees, or $33.6 \%$. Range also showed a significant decrease, losing 74 employees, or $12.9 \%$. Forestry, however, though vacillating throughout the decade, ended with a net change of near zero (-41 employees, or a $0.3 \%$ decrease).

Changes in the number of Administration and Clerical employees were surprisingly large. Clerical lost 1,043 employees, for a $26.5 \%$ decrease, while Administration gained 1,711, for a $22.7 \%$ increase. Administration employees' representation among total agency employment thus increased by 4.7 percentage points (Figure 1), the greatest proportionate increase of any category. 


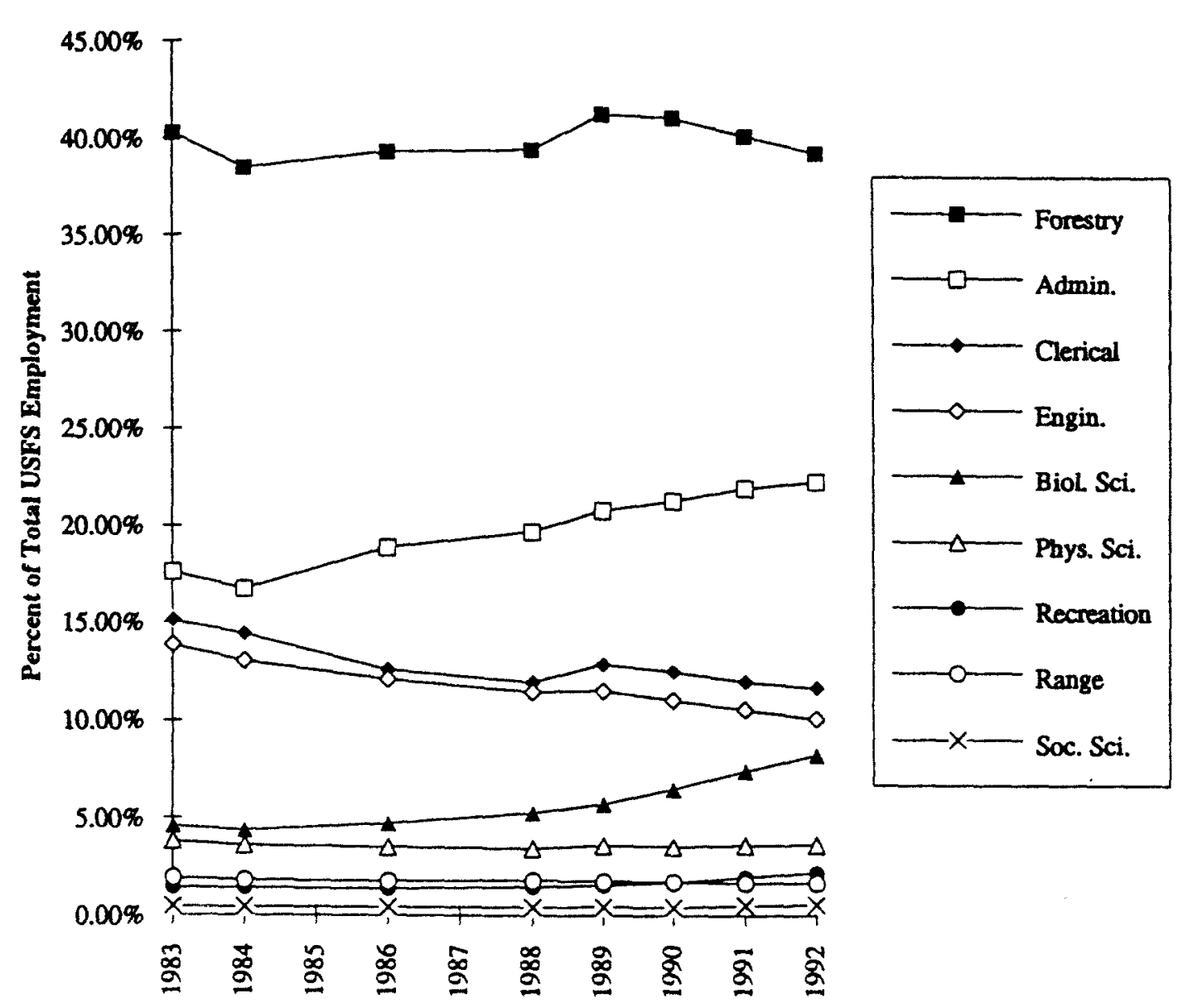

It is interesting to note that, although the number of Foresters has increased markedly, as did the total number of Forest Service employees, the percentage of Foresters within the agency decreased (Figure 1). Thus the increases in total employment in recent years came from sources in addition to Forestry. Figure 1 suggests that the balance of the increase came from the Biological Science and Administration categories.

Despite these changes, it is clear from Figure 1 that the relative proportions of employees in each category stayed nearly the same during this period. Forestry was and still is the largest category, far surpassing all others in total number of employees and percentage of all agency employees. Forestry is followed by Administration, then Clerical, Engineering, Biological Science, Physical Science, Recreation, Range, and Social Science. The only change in relative size occurred with Range and Recreation; by 1990, Recreation surpassed Range in number of employees and percentage of total Forest Service employment.

Clearly, traditional professions continue to far outweigh nontraditional professions. In 1992, in fact, Forestry, Engineering, and Range together made up 51\% of the agency, while Biological Science, Social Science, Recreation, and Physical Science together comprised only $15 \%$. 


\section{Gender Diversification}

To assess the Forest Service's efforts to achieve gender diversity, changes were analyzed in the number of female employees in the agency as a whole and in the nine categories used above. The categorization scheme represents an attempt to determine what type of jobs women have moved into, and whether they are "in the pipeline" for line positions.

As shown in Table 1, the total number of employees in the Forest Service stayed approximately the same from 1983 to 1992 . During that time, however, the number of women increased by 3,665 , or $27.0 \%$, while the number of men declined by 2,970 , or $14.8 \%$. Figure 2 shows that the percentage of women in the agency as a whole increased from $30.0 \%$ in 1983 to $40.3 \%$ in 1992 . For comparison, note that in $198042.4 \%$ of the total United States civilian workforce were women and in 1991 45.4\% were women (United States Bureau of the Census, 1992.)

Women in the Forest Service made gains in nearly every job category from 1983 to 1992 (Table 1 and Figure 3). Not surprisingly, the largest numerical gains were made in the two largest categories: Administration ( $+1,940$ women) and Forestry $(+1,572$ women). The Biological Science and Recreation categories made the most significant gains in the percentage of women. Biological Science in 1983 was $17.0 \%$ women, increasing to $33.5 \%$ women in 1992 , for a gain of 16.5 percentage points. Likewise, Recreation was $22.7 \%$ women in 1983 and $38.8 \%$ women in 1992 , for an increase of 16.1 percentage points. All other categories except Engineering and Clerical gained percentage points in the double digits as well.

The only decrease in numbers of women occurred in the Clerical category, which lost 1,091 women during the decade. There was not a significant increase in the number of men in the category, however; recall that the Clerical category as a whole declined by 1,043 jobs. Thus the percentage of women in Clerical stayed roughly the same, at just above $90 \%$.

The average grade of women increased quite significantly during the decade. As can be seen in Figure 5, the average grade for all Forest Service employees increased from 8.3 in 1981 to 8.6 in 1992 . During this time, the average grade for men stayed

Table 1

Change in Gender Ratio of Forest Service Employees, 1983-1992

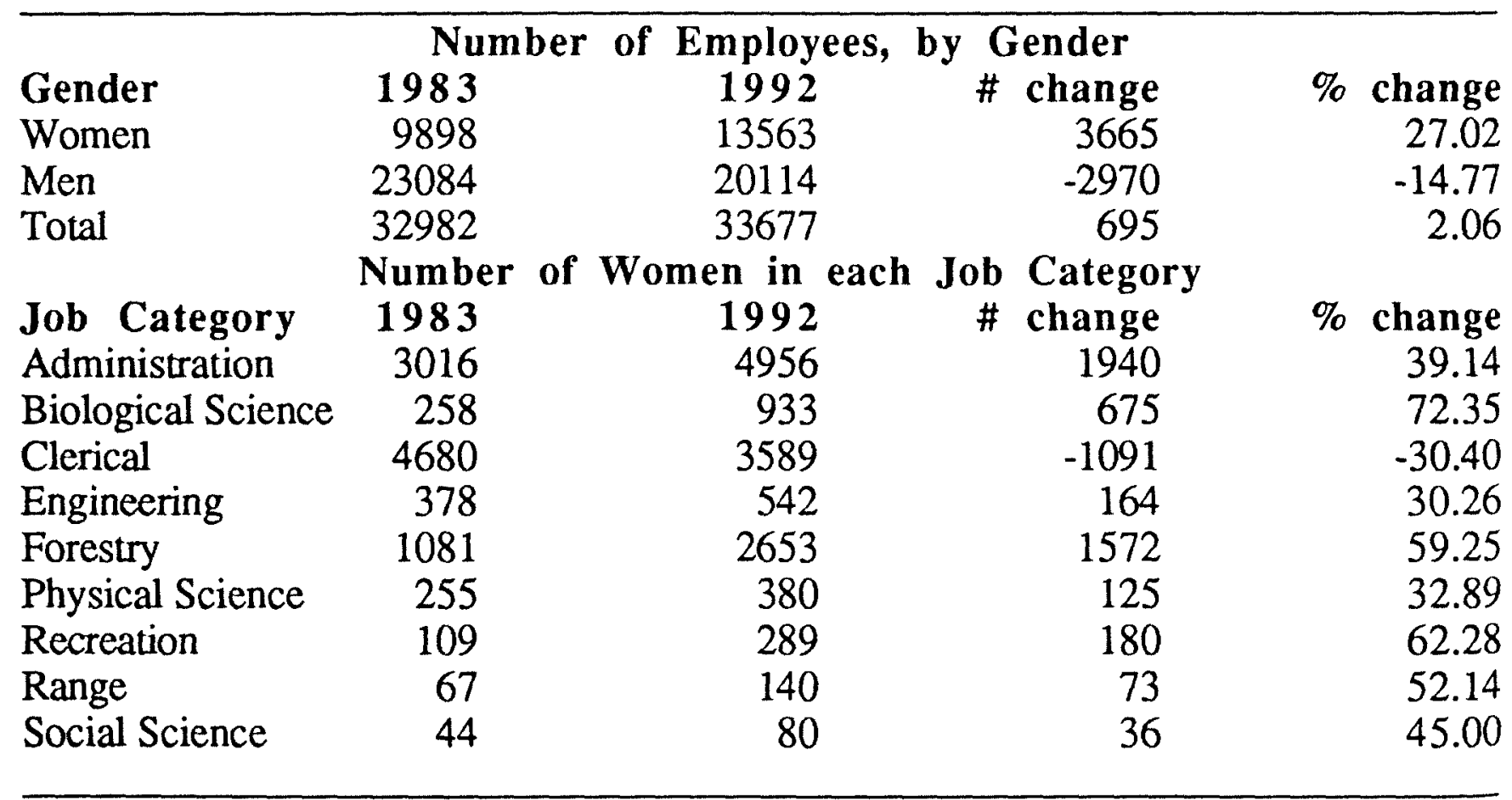




\section{Figure 2}

Gender and Race Percentages in the Forest Service, 1983-1992

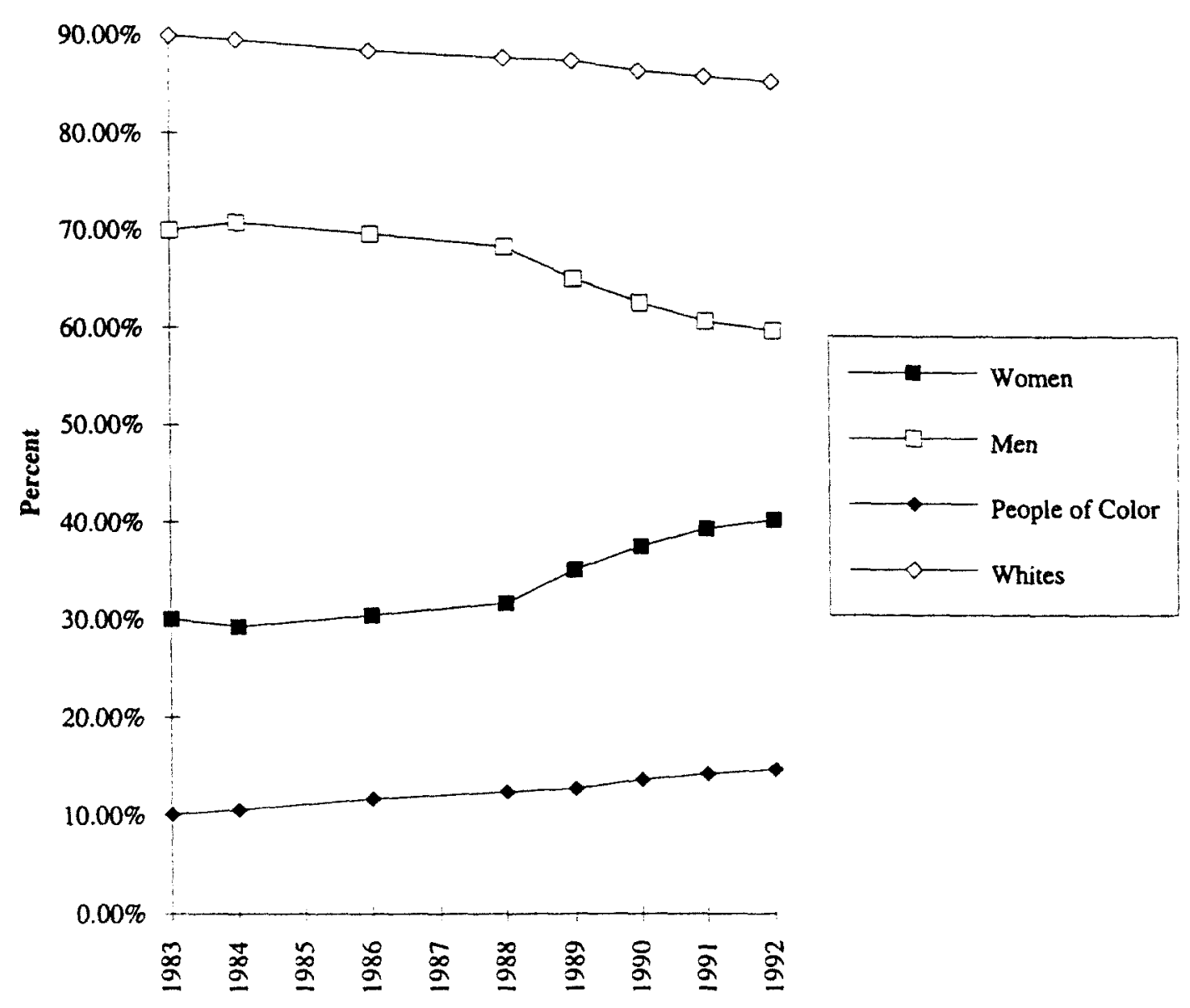

roughly the same (9.3 in 1983 and 9.4 in 1992), while for women it increased by $21.5 \%$ (5.8 in 1983 and 7.4 in 1992). Note that the average grade for women is still a full two points lower than for men, however: 7.4 , vs. 9.4 .

Despite these changes, the percentages of women in each category relative to each other stayed about the same (Figure 3). In other words, Clerical remains the category with the highest percentage of women, Administration is second, followed by Social Science and Recreation. Biological Science and Physical Science switched places, but remain the "intermediate" categories, while the percentages of women in Forestry, Range, and Engineering remain lower than other categories. Women thus remain concentrated in the categories that will not lead to line positions.

\section{Racial Diversification}

The Forest Service's achievement of racial diversification also was assessed. Recall that the total number of employees in the Forest Service remained essentially the same between 1983 and 1992. As Table 2 shows, the number of people of color increased from 3,329 to 4,946 during the same time period, for a $32.7 \%$ gain. Thus, while people of color accounted for just $10.1 \%$ of the agency in 1983, they comprised $14.7 \%$ of all employees in 1992 (Figure 2). People of color made up $12.5 \%$ of the entire civilian workforce in 1980 and $14.2 \%$ in 1991.

People of color made gains in nearly all job categories (Table 2 and Figure 4). Most significant was the large increase in the Forestry category, where people of color gained 602 jobs (an increase of $35.5 \%$ ). There also were lesser increases in the 


\section{Figure 3}

Percent of Women in Each Job Category, 1983-1992

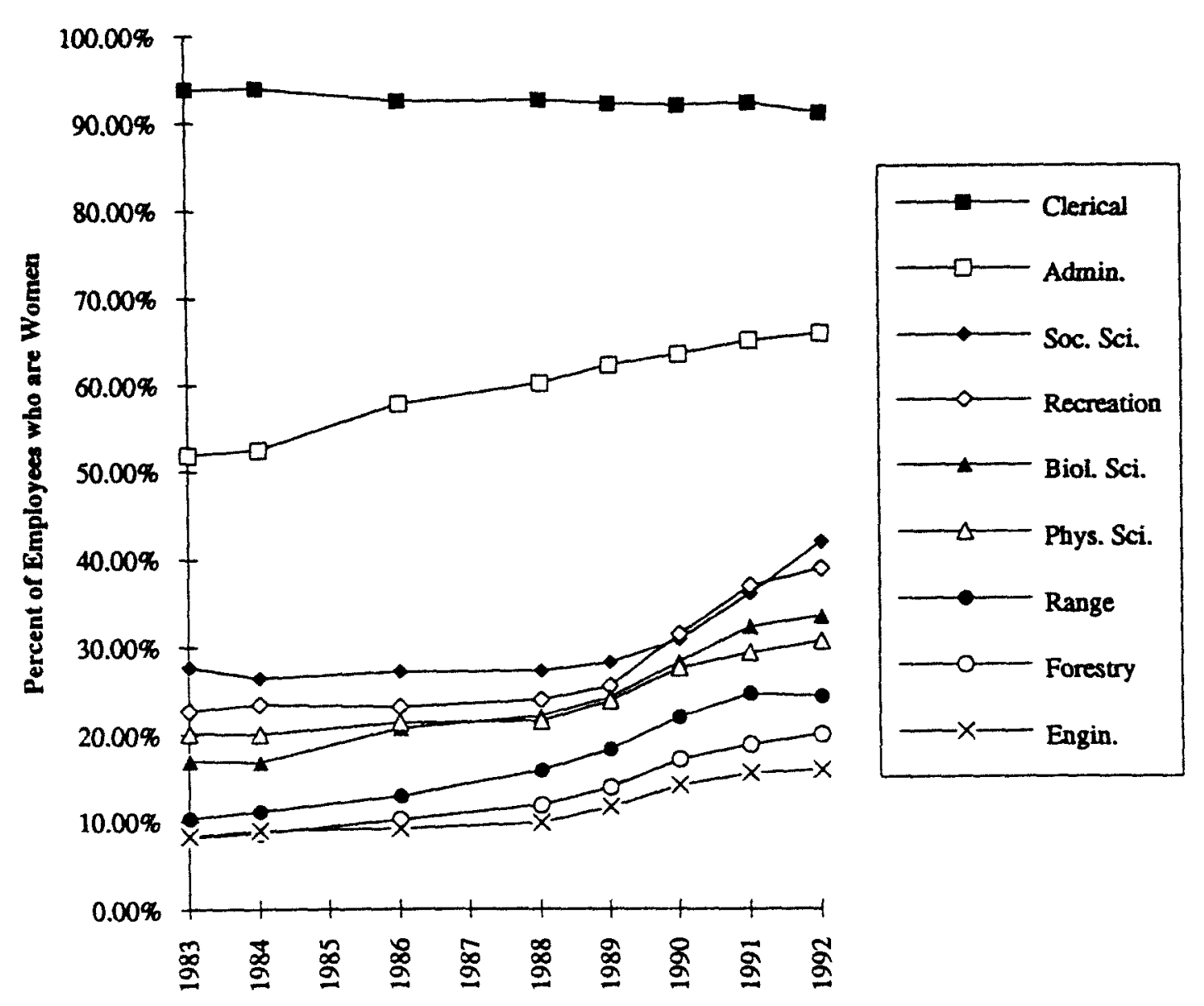

\section{Table 2}

Change in Racial Composition of Forest Service Employees, 19831992

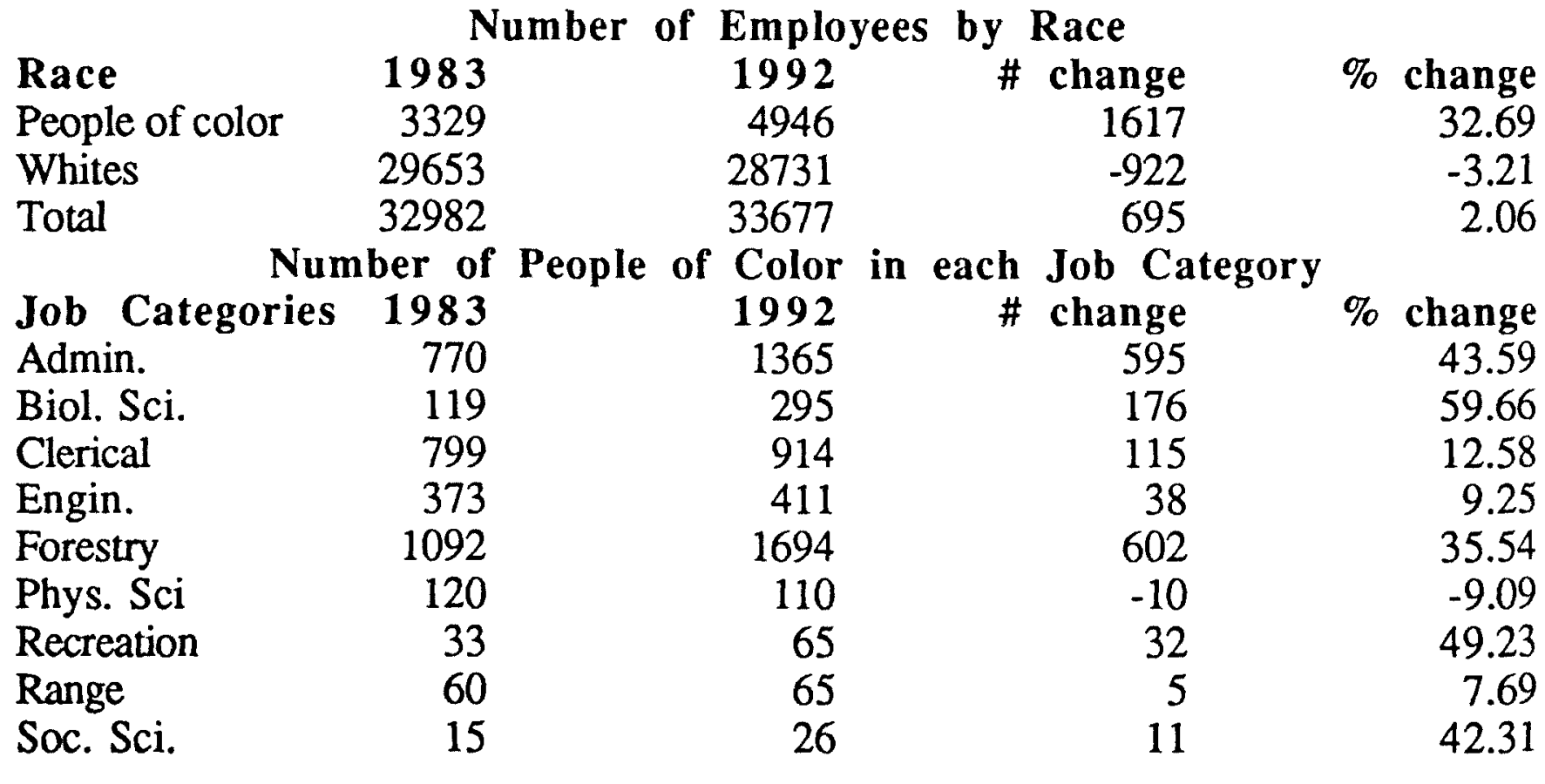




\section{Figure 4 \\ Percent People of Color in Each Job Category, 1983-1992}

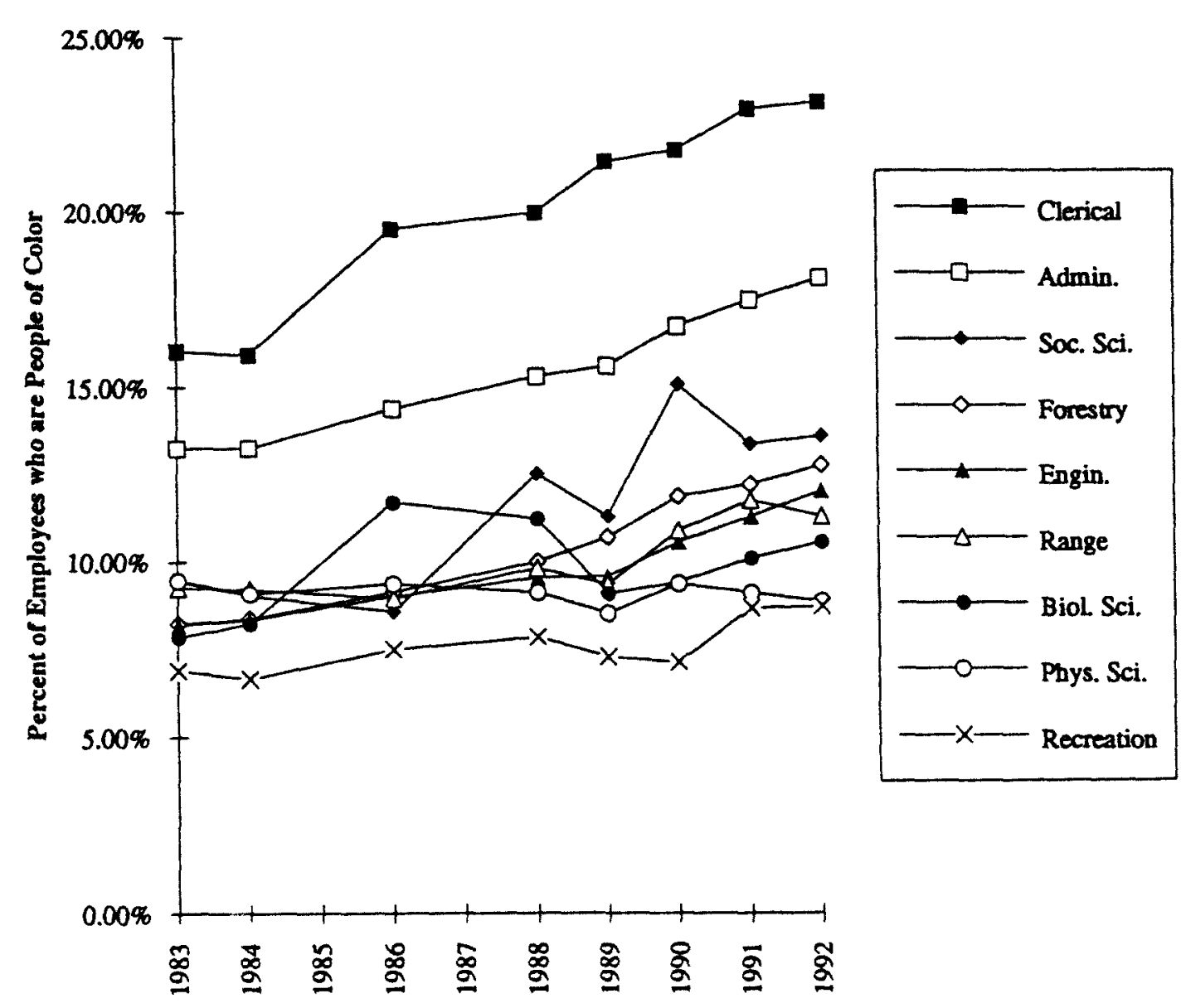

traditional categories of Range and Engineering (7.7\% and 9.3\%, respectively.)

As with women, however, the greatest gains were made in the nontraditional categories. For example, numbers of people of color in the Biological Science category increased by 176 employees, for a gain of $59.7 \%$. Likewise, Recreation and Social Science also showed increases.

The very large increases in numbers of people of color in support positions also bears mention. People of color gained 595 jobs in Administration, for an increase of 43.6\%. Although Clerical jobs decreased by more than 1,000 from 1983 to 1992 , the number of people of color in these positions increased by 115 during that period. As a result, the percentage of people of color in the Clerical category increased markedly. Looking at increases in the percentage of total employees who are people of color in each category, in fact, Administration and Clerical clearly came out ahead, with gains of 7.2 and 4.9 percentage points, respectively.

Data on the average grade of people of color were not published in the Workforce Data Books until 1988. At that time, the average grade of people of color was 7.2, compared to 8.5 for all employees (Figure 5.) The grade of people of color has risen only slightly since then, to 7.6 in 1992 . The average grade for the whole agency remained nearly the same during that time, rising one-tenth of a point to 8.6. 


\section{Figure 5}

\section{Average Grade of Forest Service Employees, 1983-1992}

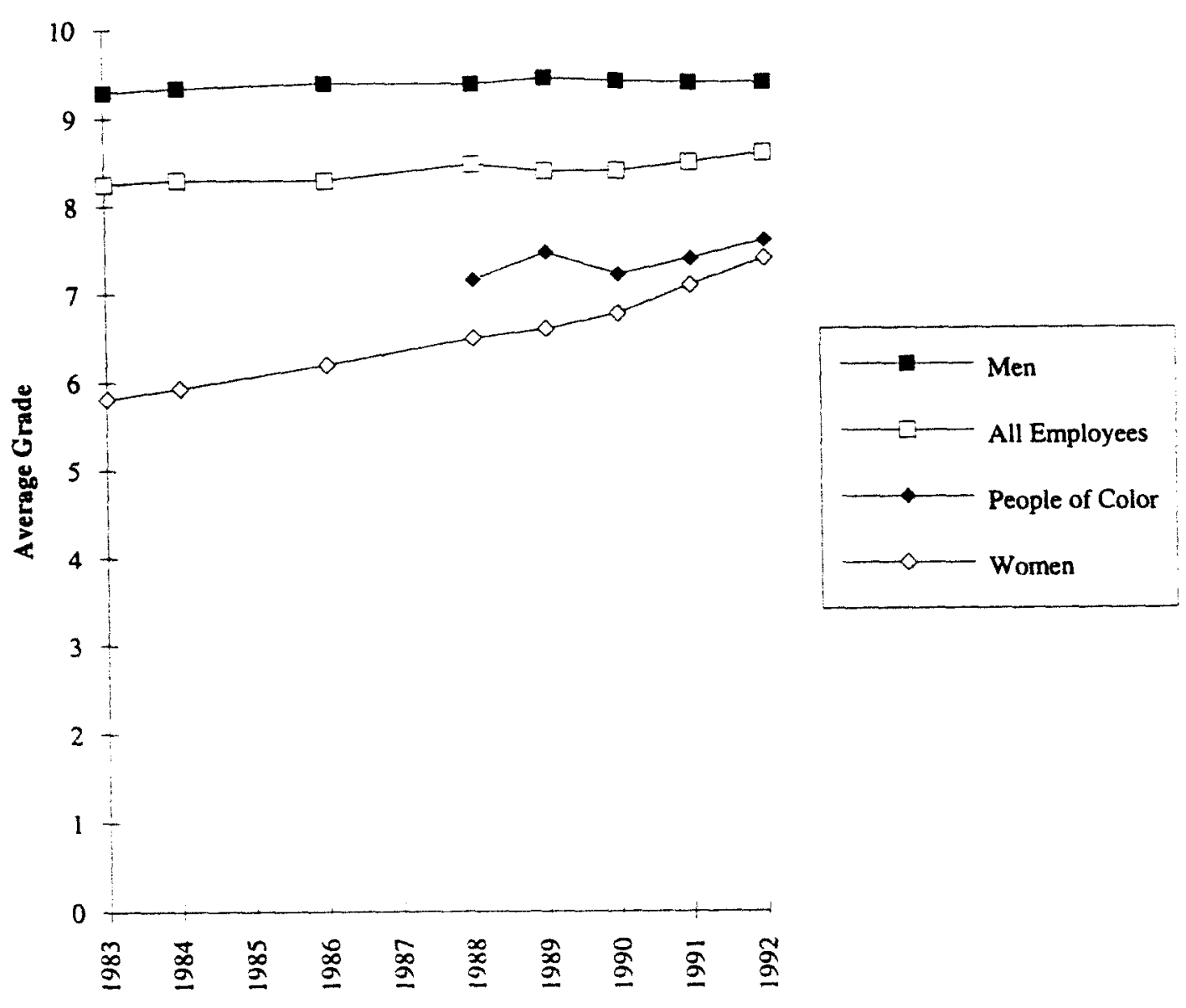

\section{Discussion and Conclusions}

The above results suggest that the Forest Service has not changed the makeup of its workforce radically, although the agency has made gains toward the goal of professional, gender, and racial diversification. In the area of professional diversification, there have been significant increases in the nontraditional professional categories and decreases in traditional categories. The large increase in Biological Science employees seems particularly important, and may reflect an attempt to increase emphasis on biodiversity, wildlife management, endangered and threatened species, and ecosystem management. The slight decrease in the Physical Science category-which includes professionals in such fields as soil science and hydrology-indicates that the diversification effort has not been uniform across nontraditional disciplines. The marked decrease in number of Engineers seems to indicate a deemphasis on some traditional Forest Service activities, such as road construction. Changes in the Clerical and Administration categories were surprising. The decrease in number of Clerical positions is due somewhat to increased office automation; the agency installed a new computer system in the mid-1980s that greatly decreased the need for clerical workers (Martin, 1993). The increase in Administration positions is less easily explained, but may have resulted from the agency's efforts to hire more women (this is explained further below). Thus, some professional diversification has taken place, but any 
discussion of an "influx" of nontraditional professionals must include as a caveat the small degree of the changes relative to the whole agency and the continued dominance of traditional professions, particularly forestry.

The Forest Service's effort to bring women into the agency appears to have been quite successful. Many more women are employed by the Forest Service now than in 1983, and the agency is much closer to matching civilian workforce percentages than before. Thus, using overall percentages as the measure of success, the agency has made significant progress. These gains have not been uniform throughout the agency, however. Women remain significantly underrepresented in the Forestry, Engineering, and Range categories, from which most line officers are chosen. Few women are "in the pipeline" to take over once new positions open up. In addition, women are overrepresented in the stereotypically "female" jobs like those in Clerical and Administration, where employees have no opportunity to reach line positions. Women's best opportunities may come in the intermediate categories of Biological Science, Recreation, Physical Science, and Social Science; women comprise a relatively high percentage of these employees, and as more of these nontraditional professionals become line officers, many are likely to be women.

The drastic decrease in number of women in the Clerical category and the concurrent increase in women in Administration is puzzling. It suggests that many women simply were moved from one type of support position to another. Although the Clerical category as a whole decreased primarily because of office automation, it is not known why the Administration category increased. A Forest Service personnel official said that "there has been a tendency in the last ten years in administrative jobs ... to advertise internally, let clerical people apply, and so move them into these positions" (Martin, 1993). This change explains, in part, the increase in average grade for women; i.e., not only have women been promoted, but some of the lowest-grade clerical positions have been eliminated

Clearly, the total numbers and percentages of people of color within the Forest Service have risen over the past decade. In fact, data presented here show that in 1991 the percentage of people of color in the Forest Service actually exceeded that of the entire civilian workforce: $14.7 \%$ people of color in the Forest Service and $14.2 \%$ in the labor force. These numbers can be deceiving, however, for there are disparities among races. For example, while the percentage of Native Americans in the agency is higher than that in the overall workforce, African Americans are significantly underrepresented in the agency (United States Department of Agriculture, Forest Service, 1992c). For the most part, today people of color seem to be concentrated in the lowest-level positions in the Forest Service. For example, people of color are highly overrepresented in the Administration and Clerical categories, where they make up $18.2 \%$ and $23.2 \%$ of the employees, respectively. In all other job categories they are underrepresented; the next-highest is Social Science (13.6\%). The very small change in average grade seems to confirm the fact that most of the people of color hired during the past decade moved into low-level jobs. However, the increase in Forestry suggests that people of color also have made progress in the category that traditionally yields the most line officers.

In sum, our analysis shows that over the past decade there has been some progress in increasing the numbers of women, people of color, and nontraditional professionals in the Forest Service. In spite of these gains, however, women and people of color still are concentrated in the nonprofessional job categories. The increasing numbers and proportions are encouraging for those who view workforce diversification as an important goal for the agency, but currently they appear to us still to be too small to suggest that workforce diversification has been an important force for 
change in the collective value orientation within the agency, as some have hypothesized (e.g., Tipple \& Wellman, 1991; Kennedy, 1991; Brown \& Harris, 1992). Rather, it may be more an effect of other "forces" at work on the agency (Mohai, 1995; Jones \& Mohai, 1995). Nevertheless, for those interested in attaining workforce diversification as a goal, the direction of change should be encouraging. And with sufficient magnitude it may result in the attitudinal and concomitant behavior changes that have been hypothesized.

\section{$* * *$}

Jennifer C. Thomas is a mediator with The Keystone Center, a nonprofit organization specializing in environmental policy dispute resolution. Ms. Thomas convenes and facilitates multiparty dialogues on national-level policy issues concerning the environment, natural resources, energy, and health. Ms. Thomas recently completed her master's degree at the University of Michigan's School of Natural Resources and Environment, where the research for this article was conducted. She holds a Bachelor's degree in biology from Principia College, Elsah, Illinois.

Paul Mohai is an associate professor in the School of Natural Resources and Environment at the Univerity of Michigan, Ann Arbor. He is principal investigator of the University of Michigan Forest Service Survey, which examined Forest Service employees' views about change and the need for change in the agency. He also is a past principal investigator of the University of Michigan's Detroit Area Study, which in 1990 examined black and white differences in concerns about envrionmental quality issues. He teaches courses in environmental sociology and natural resources policy at the University of Michigan, and has published widely on the topics of environmental attitudes and activism, natural resource agency decisiomaking, and environmental justice.

\section{Notes}

1 PATCO stands for Professional, Administrative, Technical, Clerical, and Other, and is one system the agency uses to categorize its workforce.

2 Line officers include the chief, associate chief, deputy chiefs, regional foresters, deputy regional foresters, forest supervisors, deputy forest supervisors, research station directors, project leaders, district rangers, and several others. The rest of the agency is "staff."

${ }^{3}$ GS stands for General Schedule, and refers to one way the agency delineates job positions according to level of pay.

${ }^{4}$ It is assumed that the Clerical category used here is comparable to PATCO's clerical category.

\section{References}

Blocker, T. J., \& Eckberg, D. L. (1989). Environmental issues as women's issues. General concerns and local hazards. Social Science Quarterly, 70 (3), 586-593.

Brown, G., \& Harris, C. (1992). The U. S. Forest Service: Changing of the guard. Natural Resources Journal, 32,449-466.

Brown, G., \& Harris, C. (1993). The implications of work force diversification in the U. S. Forest Service. Administration and Society, 25 (1), 85-113.

Burrus-Bammel, L. L. (1989). Women and sexism in forestry: An update. Women in Natural Resources, $11(3), 23-27$.

Garcia, M. (1989). Forest Service experience with interdisciplinary teams developing integrated resource management plans. Environmental Management, 13 (5), 583-592.

Gladics, F. (1991). The Forest Service: An agency in transition. Washington DC: National Forest Products Association. 
James, C. (1991). Women in the Forest Service: The early years. Journal of Forestry, 27 (3), 14-17.

Jones, E. S., \& Mohai, P. (1995). Is the Forest Service keeping up with the times? Interest group and forestry school perceptions of post-NFMA change in the United States Forest Service. Policy Studies Journal, 23 (2), 351-371

Kaufman, H. (1960). The forest ranger. Baltimore, ND: Johns Hopkins University Press.

Kennedy, J. J. (1991). Integrating gender diverse and interdisciplinary professionals into traditional U. S. Department of Agriculture-Forest Service culture. Society and Natural Resources, 4, 165-176.

Martin, T. (1993, February 27). Personal communication with Thomas Martin, Personnel Management Specialist, Personnel Department, United States Department of Agriculture, Forest Service.

Mayberry, B. D. (1975, February 24). Speech given at the Workshop on Entry of Minorities into Natural Resource Careers, Tuskagee Institute. Tuskagee, Alabama.

McCarthy, C., Sabatier, P., \& Loomis, J. (1991). Attitudinal change in the Forest Service: 1960-1990. Paper presented at the 1991 Annual Meeting of the Westem Political Science Association, Seattle, WA.

Mohai, P. (1990). Black environmentalism. Social Science Quarterly, 71 (4), 744-765.

Mohai, P. (1992). Men, women, and the environment: An examination of the gender gap in environmental concem and activism. Society and Natural Resources, 5, 1-19.

Mohai, P. (1995). The Forest Service since the National Forest Management Act: Assessing bureaucratic response to extemal and internal forces for change. Policy Studies Journal, 23 (2), 247-252.

Mohai, P., Stillman, P., Jakes, P., \& Liggett, C. (1994). Change in the USDA Forest Service: Are we heading in the right direction? General Technical Report NC-172. St. Paul, MN: United States Department of Agriculture, Forest Service, North Central Experiment Station.

Robertson, D. (1988, January 12). Speech given to the Forest Service Servicewide Civil Rights Committee, the Forest Service Southwestern Region Civil Rights Committee, and the Forest Service Civil Rights Directors, Ramada Classic Hotel, Albuquerque, NM.

Tipple, T., \& Wellman, D. (1991). Herbert Kaufman's forest ranger thiny years later: From simplicity and homogeneity to complexity and diversity. Public Administration Review, 51 (5), 421-428.

Twight, B. W. (1983). Organizational values and political power: The Forest Service versus the Olympic National Park University Park and London: Pennsylvania State University Press.

United States Bureau of the Census. (1992). Statistical abstracts of the United States. Washington, DC.: United States Govemment Printing Office.

United States General Accounting Office. (1990). U. S. Department of Agriculture: Need for improved workforce planning. GAO/RCED-9--97. Washington, DC: Author.

United States Department of Agriculture, Forest Service. (1992a, February 14). Briefing paper on the consent decree accompanying the 1993 budget request. Washington, DC: Author.

United States Department of Agriculture, Forest Service. (1992b). Toward a multicultural organization: Implementation plan. Washington, DC: United States Department of Agriculture, Forest Service, Task Force on Work Force Diversity.

United States Department of Agriculture, Forest Service. (1992c). Work force data book: 1991-1992. [Equivalent reports were used for the years 1982, 1983, 1985-1986, 1987, 1988-1989, 19891990, and 1990-1991]. Washington, DC: United States Department of Agriculture, Forest Service, Personnel and Civil Rights Staff.

United States Department of Agriculture, Forest Service. (1990). Equal opportunity is for everyone: 1990 accomplishments. Washington, DC: United States Department of Agriculture, Forest Service, Personnel and Civil Rights Staff.

United States Department of Agriculture, Forest Service. (1987). Work force 1995: Strength through diversity. Washington, $\mathrm{DC}$ : Author.

West, T. (1992). Centennial mini-histories of the Forest Service. Washington, DC: United States Department of Agriculture, Forest Service. 
This document is a scanned copy of a printed document. No warranty is given about the accuracy of the copy. Users should refer to the original published version of the material. 